\title{
Değişen Finansal Akımlar: Rasyonalizmden Davranışsal Finans Yaklaşımına
}

\author{
Nazlı Gamze SANSAR*
}

Öz

Klasik finans teorilerinin piyasa anomalilerini açıklamada yetersiz kalması bu alanda yeni teorilerin ortaya çıkmasıyla sonuçlanmıştır. $\mathrm{Bu}$ anlamda geleneksel finansçıların temel çıkış noktalarından olan ve temelleri Fama tarafından 1960'larda atılan Etkin Piyasa Hipotezine karşı geliştirilmiş Davranışsal Finans yaklaşımı, yatırımcların geçmişten günümüze değişime uğrayarak yatırım kararlarında tam anlamıla rasyonel davranmadıklarını ve aldıkları yatırım kararlarında bazı psikolojik faktörlerin etkisi altında olduğunu savunmaktadır. İnsanın doğası gereği karar alma süreçlerinde rasyonel davranışların yanı sıra duygu ve kişisel sezgilerinin de geniş bir yer tuttuğu ve bu özelliklerin davranışlara son halini verdiği görülmektedir. Bu çalışmanın amacı finansal piyasa katılımcılarının yatırım kararlarına etki eden psikolojik faktörleri belirtmek ve bu faktörler arasındaki ilişkiyi ortaya koymaktır. Bu amaçla yatırım kararlarına optimal gerçeklik kazandırarak yatırımcı varlıklarının, yatırımcının doğası içerisindeki kusurlarından dolayı erimesine engel olmak ve yatırımcılara kendi özelliklerini göz önünde bulundurarak doğru yatırım kararları almasına olanak sunmaktır.

Anahtar Kelimeler: Etkin Piyasalar Hipotezi (EPH), Davranışsal Finans, Yatırımcı ve Psikolojik Faktörler

\section{Changing Financial Flows: \\ From Rationalism to Behavioral Finance Approach}

\begin{abstract}
New search in the field of anomalies of the market has started, as a result of traditional financial theories become inadequate to explain the ground. In this sense
\end{abstract}

DOI: http://dx.doi.org/10.17336/igusbd.27952

* Yrd. Doç. Dr., İstanbul Gelişim Üniversitesi, İİSBF Öğretim Üyesi,

E-posta: ngsansar@gelisim.edu.tr 
Efficient Market Hypothesis which marks the starting point of the traditional finance, improved by Fama, was thrown in 1960 by Behavioral Finance approach, arguing that investors do not behave rationally in their investment decisions because of the influence of some psychological factors. Advanced human nature, as well as personal feelings and intuition of rational behavior also seems to hold a large place at these factors. The purpose of this article is to study psychological factors affecting the application investment decisions of participants by reviewing their hair up and reveal

Sayfa/Page | 136 İGÜSBD Cilt: 3 Sayı: 2 Ekim / October 2016 the relationship between these factors. With this purpose, it is aimed to shed light to optimal investment decisions by offering investors the existence of reality, to prevent melting of invesments because of imperfections in the nature of investors and to provide opportunities to make the right investment decisions to investors.

Keywords: Efficient Market Hypothesis (EMH), Behavioral Finance, Investors and Psychological Factors

\section{Giriș}

Finansal piyasalarda birçok yeni yaklaşım, teori ve hipotez özellikle son yüz yılda büyük artış göstermiştir. Birçok finansçı ve akademik yazın piyasa anomalilerini sebep-sonuç ilişkisi içerisinde açılamaya çalışmış, finans dünyasında önemli yer edinen Etkin Piyasa Hipotezi, Rassal Yürüyüş, Beklenti Teorisi vb. ölçülebilir finansal yaklaşımları günümüzde evrim geçirerek yeni bir hal almıştır.

Klasik finans teorilerinin finansal davranışları açıklama için oluşturduğu model ve denklemler, yatırımcıların söz konusu modellemelerdeki varsayımlardaki gibi "rasyonel" davranmadığının izlenmesinin sonucu davranışsal finansı doğurmuştur. Davranışsal Finans, piyasadaki değişimleri insanların irrasyonel davranışlarına bağlayan, ekonomik karar alma mekanizmalarının sosyal ve duygusal dürtülerden nasıl etkilendiği üzerine araştırmalar yapan ve genel olarak, fiyat değişimlerinin rasyonel faktörlerden daha çok irrasyonel faktörlerin/olguların etkisinde olduğunu ve bunları da kapsayan bazı modelleri açılklayan bir yaklaşımdır.

Bu anlamda, Jim Rogers "yatırımlar kadar yatırım karşısında takınılacak tavır da önemlidir" sözü ile yatırımcılar için yatırım kararlarının finansal tekniklerle belirlenmesinden sonra, duygu ve bilişsel tavırlarıyla da söz konusu kararı sürdürebilme yeteneğine sahip olmaları gerektiğini özetlemiştir. Davranışsal finansın ana amacı ölçülebilir finansal yaklaşımlarının yanlış olduğunu ispat etmek değil, yatırımcıların sadece 
finansal tekniklerle karar almadığını ve bu kararlarının psikolojik hakimiyetle daha optimal bir hale dönüşeceğini açıklamasıdır. Kısacası, gelişmiş insan beyninin, ilkel yapısıyla olan bağlantısını finansal işleyiş içerisinde anlatmak, sebeplerini sunabilmek ve konu hakkında farkındalık yaratabilmektir.

Teori olarak Davranışsal Finans ise; temelleri Fama tarafından 1960'ta atılan Etkin Piyasalar Hipotezine bir eleștiri, zayıf etkin piyasalara da örnek olarak ortaya çıkmıştır. Akımın son yıllarda popüler hale getiren sebep ise, 2008 krizi döneminde mortgage fiyatlamalarında rasyonel fiyatlamanın başarısız olması ve fiyatlamanın içerisinde insana özgü algıların da var olduğu gerçeğidir. Davranışsal Finans teorisi daha sonra ise birçok akademisyen ve finansçı tarafından zenginleștirilerek tüm finansal piyasalara uygulanmış ve piyasa anomalilerindeki temel sebeplerin insani zaaflardan oluştuğu gerçeğine ulaşmıştır.

$\mathrm{Bu}$ bağlamda yapılan çalışmalar ile klasik finans modellerinde öngörülenin aksine yatırımcıların "rasyonel" hareket etmedikleri ve tercihlerini optimize edemedikleri ortaya çıkmıștır. Bilişsel sınırlar, psikolojik önyargılar, belirsizlik, geçmiş tecrübeler gibi olgular, yatırım ve finansal kararlarda yatırımcıların rasyonellikten uzak, sezgi ve hislerin kontrolünde davranmalarına neden olmaktadır. Davranışsal Finans teorisi ise, insanı "rasyonel" olarak kabul eden klasik teori ve modellere alternatif olarak geliştirilmiş, irrasyonalite ve insan psikolojisinin yatırım kararlarına etkisi üzerinde durmuştur. Varlık fiyatlarında sezgi, alışkanlık ve geçmiş tecrübelerin de önemli rol oynadığının ortaya çıkmasıyla birlikte Davranışsal Finans teorisi ekonomik modellerde yoğun olarak kullanılmaya başlanmıştır.

Bireylerin rasyonel hareket ettikleri varsayımı başta Beklenen Fayda kuramı ve Etkin Piyasalar Hipotezi olmak üzere birçok klasik finans ve ekonomi kuramına dayanak oluşturmuştur. Davranışsal Finans ise yatırımcıların risk ve belirsizlik durumları oluştuğunda karar alırken psikolojik ve sosyolojik faktörlerden de etkilendiğini öne süren interdisipliner bir teoridir. Davranışsal Finans teorisinde yatırımcılar, klasik portföy teorisinin aksine, bir takım bilişsel kusurlar ile bu kusurların neden olduğu ve rasyonelliğe uymayan bir takım zihinsel kısa yollarla davranabilmekte, varsayımlar ile rasyonellikten uzaklaşabilmektedir.

Sayfa/Page | 137

İGÜSBD

Cilt: 3 Sayı: 2 Ekim /

October 2016 


\section{ETKIN PIYASA HIPOTEZI}

1965 yılında Etkin Piyasa Hipotezini ortaya çıkaran Fama, etkin piyasaları "rasyonel ve kar amaçlı bireylerden oluşan" ve sonucunda da "ürünlerin/hizmetlerin gerçek fiyatını bulduğu yer" olarak tanımlamaktadır. ${ }^{1}$

Sayfa/Page | 138 İGÜSBD Cilt: 3 Sayı: 2 Ekim / October 2016 Etkin Piyasa Hipotezi piyasalardaki tüm bilgilerin bütün piyasa katılımcıları tarafından ulaşılabilir olduğu için fiyatların içerisinde olduğunu, kimsenin bilmediği ve para kazanmak için kullanılabileceği bir bilginin olmadığını varsayar. Bu nedenle örneğin, yatırımcının piyasaların geçmiş fiyat verilerini kullanması, böylelikle herkesten çok para kazanması teoride mümkün değildir. Söz konusu hipotezin tartışmalı bir diğer varsayımı ise, fiyatların doğruluğudur. Etkin Piyasa Teorisinin varsayımına göre piyasada oluşan fiyatlar, varlıkların gerçek değerini yansıtır, doğrudur ve bir fiyat balonunun oluşması da bu nedenle mümkün değildir. ${ }^{2}$

Etkin Piyasa Hipotezi ile ilgili en çok tartışılan ve bu iki konu Davranışsal Finans Teorisinin ortaya çıkış nedenlerinden en önemlileridir. Etkin Piyasa Teorisinin varsayımlarından biri olan rasyonalite ve piyasada oluşan fiyatların doğru olarak kabul edilmesi Davranışsal Finans tarafindan farklı yönleriyle irdelenmektedir.

\section{BEKLENTI TEORÍSi}

Etkin Piyasa Teorisinde yer alan yatırımcı rasyonelliği; yatırımcının karar verirken analizler yaparak en doğruyu seçtiğini ve bunu sürekli ve tutarlı bir şekilde yaptığını varsayar. Bu çerçevede "rasyonellik" tutarlılıkla ilişkili bir varsayımdır.

Miller and Modigliani, 1961 yılında temettüler üzerine yayınladıkları makalede yatırımcıları "rasyonel" olarak tarif ederler. Rasyonel yatırımcılar, "her zaman daha fazla kazancı daha azına tercih ederler ve kazancın türü (nakit ya da hisse senedi değer artışı olması) onlar için önemli değildir." 3 Shefrin ve Statman'a göre ise yatırımcların belirli bir hisse senedine sahip

${ }^{1}$ Orhan Erdem, "Değișen Teoriler ve Davranışsal Finans", 26 Ağustos 2015, http://www.bilgi.edu.tr/site_media/uploads/files/2015/08/26/ekonomideparadigma-150824.pdf?, (Erişim Tarihi 12 Ocak 2015), s.1.

${ }^{2}$ A.g.m, s. 2 .

${ }^{3}$ M. Miller ve F. Modigliani, "Dividend policy, growth, and the valuation of shares", Journal of Business, 34 (4), 1961, s. 411-433. 
olma nedenleri sadece rasyonel yatırım kararları değil; arzuları, duyguları ve bilişsel hatalarıdır. ${ }^{4}$

Yatırımcıların her daim rasyonel davranmadığını savunan bu tür akademik çalışmalar genellikle deneyler ile savunulmaktadır. Daniel Kahneman ve Amos Tversky 1979 tarihli "Beklenti Teorisi: Risk Altında Karar Vermenin Bir Analizi" adlı çalışmalarında Beklenen Fayda Teorisinin yetersizliklerinden yola çıkarak, insanın belirsizlik altında nasıl karar verdiğini anlatan ve rasyonaliteye dayanan, Beklenti Teorisi'ni ortaya koymuşlardır.5 Beklenti Teorisi'ne göre yatırımcllar memnuniyet veya memnuniyetsizlik duygularını belirli bir referans noktası çerçevesinde oluşturmakta ve söz konusu referans noktasından uzaklaştıkça kazanç veya kayıp algısı da değişkenlik göstermektedir. Beklenti teorisinin "kayıptan kaçınma" özelliğinden dolayı değer fonksiyonda, kayıplar kazançlardan daha diktir. Teori, insanların ellerindekinden vazgeçmeleri için, o şeye sahip olmak için verdiklerinden daha fazlasını istedikleri varsayımı üzerine kuruludur. 6

Beklenti Teorisine göre karar alma; düzeltme ve değerlendirme süreçlerinden oluşmakta, yatırımcılar, kararlar alırken bu süreçlerden geçmektedirler. Düzeltme sürecinin ilk aşaması kodlama safhasından oluşmaktadır. Kodlama safhası her şeyden önce, ilk olarak referans noktasının belirlendiği safhadır. Referans noktasının belirlenmesini takiben, mevcut durum incelendiğinde, mevcut durum referans noktasının altında kalıyorsa kayıp olarak, üstünde kalıyorsa kazanç olarak kodlanmaktadır. Sürecin ikinci safhası ise kombinasyon safhası olarak adlandırılmakta, bu safha eşdeğer çıktıların olasılıklarının birleştirilmesi ile bir anlamda basitleştirmeye gidilmesidir. Son safha ise iptal etme safhasıdır. Bu safhada her seçenekte yer alan ortak beklenti ve olasılıklar iptal edilerek seçeneklerin biraz daha basit hale getirilmeye çalışıldığı aşamadır. Düzeltme sürecini takiben, değerlendirme aşamasında ise analizi yapılarak önerilmiş beklentiler değerlendirilerek, sonucunda en yüksek değeri olan olasılıktan yana tercihte bulunulur. Böylelikle, beklenti teorisinde yatırımclar, getirilerini son servet durumlarına göre değil, belirlemiş oldukları referans noktasından oluşan olumlu ya da olumsuz sapmalar şeklinde değerlendirmektedir.

${ }^{4}$ H. Shefrin ve M. Statman, "Explaining investor preference for cash dividends", Journal of Financial Economics, 13 (2), 1984, s. 253-282.

${ }^{5}$ Michael Scharge, "Daniel Kahneman: The Thought Leader Inteview", Strategy + Business, 2003, s. 1-6.

${ }^{6}$ C. Fox Trepel...et al., "Prospect theory on the brain? Toward a Cognitive

Neuroscience of Decision Under Risk", Cognitive Brain Research, 2005, s.37.

Sayfa/Page | 139

İGÜSBD

Cilt: 3 Sayı: 2

Ekim /

October 2016 
Sayfa/Page | 140

$\mathrm{Bu}$ teoriye göre; yatırımcılara hisse senedine yatırım yapmaları durumunda \%80 olasılıkla \%30'luk fiyat artış kazancı ve \%20 olasılıkla kazanamamak ile \%100 olasılıkla \%15'lik fiyat artış kazancı seçenekleri sunulduğunda, yatırımcıların geneli \%15'lik kazancı tercih edecektir. Gene teoriye göre; yatırımcılara $\% 80$ olasılıkla $\% 30$ reel değer azalış zararı ve $\% 20$ olasılıkla hisse senedi fiyatlarının sabit durması ile hiçbir şey kaybetmemek ile \%100 olasılıkla \%15 reel değer azalışı arasında bir seçim yapmaları istenmesi durumunda ise, yatırımcıların geneli \%30'luk reel değer azalış zararını tercih ederler. Bunun nedeni ise, yatırımcının gerçekte kazançlarla ilgili olarak riskten kaçınması, kayıplar için ise risk alması olarak açıklanmaktadır.

Beklenen Fayda Teorisinin eksik kaldığı noktalardan hareketle ortaya konan Beklenti Teorisi bazı temel noktalarda Beklenen Fayda teorisinden ayrılmaktadır. En temel farklılık, Beklenen Fayda teorisinde karar alma rasyonel bir süreç olarak ele alınırken, Beklenti Teorisinde bu rasyonelliğin geçerli olmadığı, kişilerin kararlarında kendi beklentilerinin ön planda olduğu ifade edilmiştir. Buna göre, Beklenen Fayda Teorisinde net nakit girişleri yatırımcının kararlarında dikkate aldığı bir unsur olarak değerlendirilirken, Beklenti Teorisinde belirlenen referans değerlerinin altında ya da üstünde kalmak yatırımcıların kararlarını şekillendiren bir unsur olmaktadır.

\section{DAVRANIŞSAL FINANS İÇİNDEKİ PSİKOLOJİK EĞİLIMLER}

Davranışsal Finans teorisinde öncelikle; asıl neden ne olursa olsun, insan beyni rasyonel karar almada düşünülenin aksine yanıltıcı bir araç olabilmektedir. Yani Klasik İktisat teorisindeki rasyonel davranış varsayımı, Davranışsal Finans teorisyenlerinin bulgularıyla örtüşmemektedir. Klasik ekonomi teorisi insanoğlunun sabit tercihlere sahip olduğunu ve rasyonel davranarak bu tercihler ışığında maksimum fayda elde etmek için uğraşacağını varsayarken, Davranışsal Finans yaklaşımı ise insanların irrasyonel davranışlarda da bulunduğunu ve bu davranışların temel sebebinin ise psikolojik önyargılar olduğunu savunmaktadır.

Psikolojik ön yargılar, bilginin depolanması ve tecrübeler, bilginin işlenmesindeki algı hatalar ve karar sürecinde oluşan hatalardan oluşmaktadır. Ön yargılar ise iki ana başlık altında; hevristik ile bilişsel önyargllar ve duygusal faktörler olarak şekillenmektedir. Hevristik ve bilişsel önyargılar, problem çözmede çeşitli problemlere uygulanan ancak her zaman doğru çözümü sağlamayan düşünsel boyuttaki kestirme yollardır. Söz konusu 
önyargılar, aşırı bilgi ile yüklendiğinde, sorunun çözümü için zaman kısıtı olduğunda, şansa bağlı veya önemli olmayan konularda, karar aşamasında yeterli bilgi olmadığında ortaya çıkmaktadır. $\mathrm{Bu}$ nedenle de sistematik hataların ardı ardına yapılmasına neden olmaktadır.

\subsection{Beynimizin İlk Zaafı: Aşırı Güven}

Yatırımclar kendi yeteneklerine aşırı derecede güven duyma ve diğer insanlarınki ile kıyasla kendi tahminlerinin doğruluğuna daha çok önem verme eğilimindedirler.7 Söz konusu aşırı güven ise yatırımcılar için yatırım kararlarının kolaylıkla manipüle edilmesine neden olabilmektedir. Aşırı güven sahibi yatırımcılar, aldıkları risk düzeyini doğru yorumlama yetilerini kaybetme eğilimindedirler. Bu da algılanan risk düzeyini değiştirmektedir. Yatırımcılar aşırı güven sonucu portföylerinde gereğinden az çeşitlendirme yapabilmekte, bu nedenle riskin yeterince dağılmamasıyla beklenilenden daha kötü sonuçlar alınabilmektedir.

"Rasyonel" bir yatırımcı ise getiriyi maksimize etmeye çalışırken, riski de minimize etmeye çalışmaktadır. Aşırı güven sahibi yatırımcı ise, yaptığı yatırımdan oldukça emin olduğu için ve yatırımındaki riski görmez. Sonuç olarak, aşırı güven eğilimi, yatırımcının risk seviyesini ve algısını değiştirmekte ve yatırım riskini yanlış değerlendirmesine neden olmaktadır.

\subsection{Optimizim-Aşırı İyimserlik}

İnsanlar, doğası gereği yapabilecekleri konusunda gereğinden fazla iyimserdir. Bu özellik, yatırımcılar için genellikle kendi portföy getirilerinin endeks ortalamasından daha fazla getiriye sahip olacağına inanmaları olarak ortaya çıkmaktadır. Bu varsayımla yatırımcılar örneğin, Endeks 100 almak yerine kendi belirlediği endekste yer alan spesifik hisseleri almayı tercih etmektedir.

Hem aşırı güven hem de iyimserlik tutumu içinde olan yatırımcılar, piyasa hakkında elde ettikleri bilgileri ve alım-satım işlemlerindeki yetkinliklerini abartma, bununla birlikte riskleri ise önemsememe eğilimi göstermektedir. Bu tip yatırımcılar, ayrıca, elde ettikleri başarılı sonuçları

7 Zvi Bodie et al., Investments, 8th ed., Mc Graw Hill Yayınevi, Singapur, 2009, s.386.

Sayfa/Page | 141 İGÜSBD Cilt: 3 Sayı: 2 Ekim / October 2016 
kendilerine, başarısızlıkları ise dış etkenlere atfetme eğilimindedirler. ${ }^{8}$ "Rasyonel" bir yatırımcı ise fazla iyimser tutumlar sergilemekten kaçınır, sadece başarılarını değil başarısız yatırım kararlarını da dikkate alır ve yatırım kararlarını güncel veriler, analizlere dayandırır.

Sayfa/Page | 142 İGÜSBD Cilt: 3 Sayı: 2 Ekim / October 2016

\subsection{Temsilîlik}

Yatırım kararlarını etkileyen prensiplerden birisi de temsilîlik eğilimidir. İlk olarak Kahneman ve Tversky tarafından öne sürülen söz konusu eğilim ile insan beyni, benzeş özelliklere sahip olan şeylerin çok büyük oranda benzer olduğu varsayımını yapmaktadır. ${ }^{9}$ Temsilîlik genellemelere dayalı kararlardan bahsetmektedir. ${ }^{10}$ Özellikle bağımsız ve tarafsız yapılan örneklemelerin, geneli yansıttığı doğru olmakla birlikte, insanların bir olaya ilişkin örnek büyüklüğünü dikkate almama eğilimi içinde olması, stereotipleme yapmalarına yol açar.

Temsilîlik eğilimde olan yatırımcılar örneğin, dövizin belli bir süre devamlı değer kazanması ile birlikte, bir süre sonra söz konusu değerlemeyi bir genelleme haline dönüştürmektedir. ${ }^{11} \mathrm{Bu}$ da, rasyonel bir yatırıcımcının yapacağının aksine, yatırım kararlarını alırken sınırlı istatiksel bilgi ve analiz kullanmaları, bu verilerin yerine genellemeler yönünde hareket etmeleri ile sonuçlanmaktadır.

\subsection{Akli Muhasebeleștirme}

İnsanlar paranın nereden geldiği, nerede geliştiği ve nasıl harcandığına bakarak kategorize etme eğilimi içindedir. Hâlbuki rasyonel bakıldığında paranın tek bir değeri vardır, o da üstünde belirtilen rakamın alım gücüyle birleşmesidir. İnsanoğlu için ise "alın teri" ile kazandığı 3000 TL, borsada kazanılan 3000 TL'den daha değerlidir. Bu yüzden yatırımcılar genelde yatırım yaparken borsadan kazandıkları 3000 TL ile daha fazla risk üstlenebilirken, maaş olarak kazandıkları $3000 \mathrm{TL}$ ile daha az risk alırlar. Bu

${ }^{8}$ E. Langer ve J. Roth, "Heads I win, tails it's chance: The illusion of control as a function of the sequence of outcomes in a purely chance task", Journal of Personality and Social Psychology, 32, 1975, s. 951-955.

${ }^{9}$ Daniel Kahneman ve Amos Tversky, "Subjective Probability: A Judgment of Representativeness", Cognitive Psychology, Vol: 3, 1972, s. 430-454.

10 John R. Nofsinger, The Psychology of Investing, 4th ed., NJ: Prentice-Hall, 2010, s.76.

${ }^{11} \mathrm{~K}$. E. Case ve R. Shiller, "The behavior of home buyers in boom and post-boom markets", New England Economic Review, 80, 1990, s. 29-46. 
özellikten dolayı, borsada yatırım yapan bir yatırımcı, başta finansal analizler sonucunda oluşturduğu stop loss (zarar kes) seviyesini, borsada beklenmeden yaşanan değer artışları sonucunda riske atarak bu seviyeyi esnetme eğiliminde olabilirler. Rasyonel olarak bakıldığında ise aslında borsada kazanılan 3000 TL, "alın teri" ile kazanılan 3000 TL ile aynı oranda değerlidir ve alınan risk oranının da aynı olması gerekmektedir.

\subsection{Statüko Sapması}

İnsanoğlunun pişman olmaktan kaçınma dürtüsü, karar alma mekanizmasını çok güçlü bir şekilde etkilemektedir. $\mathrm{Bu}$ da insanların elindekinden vazgeçememe eğiliminde olmalarına, daha iyi bir alternatif önerildiği halde pasif kalarak, iyi bir fırsatı kaçırmalarına yol açmaktadır. $\mathrm{Bu}$ özellik aynı zamanda, yatırımcıların karar alırken, sahip oldukları varlıklara daha fazla değer biçmeleri ile sonuçlanır. ${ }^{12}$

Statüko sapması bu yüzden, yatırımcıların portföy varlıklarını satma konusunda kararsız kalmalarına yol açar ve portföy yapısını değişen şartlara karşı dönüştürebilme yeteneğini de zayıflatır. Örneğin, bu durum hisse senedine olduğundan daha fazla değer biçen bir yatırımcının, bu araçların asıl amacı olan likitide imkanını kaçırması sonucunu doğurabilmektedir. "Rasyonel" yatırımcı ile sahip olduğu değerlere karşı duygusal bir bağ yoktur, söz konusu değerlere sahip olmasının tek nedeni elde edeceği kazançtır ve kazancin türü onun için önemli değildir. Bu yüzden elinde bulundurduğu değerlemelerin fiyatlamasını objektif yapar, yatırım fırsatlarını böylelikle iyi değerlendirir.

\section{6 Çıpalama}

Çıpalama, insanların ilk gelen bilgiye takılı kalarak, sonrasında gelen bilgilere yeterli derecede adapte olamama eğilimidir. Bu eğilim yatırımcılar için, örneğin, dövizde ya da emtiada 3 TL, 5 TL gibi psikolojik beklenti içerisine girip, değişen koşullarda eski beklenti sınırını güncellememesine sebep olur. Bu durumda, pazarlık genel anlamda bir malın satışı öncesinde bahsedilen fiyat etrafında yoğunlaşmakta, bu da değişen şartlara ayak uydurulmaması sonucunu doğurabilmektedir.

12 P. Knez, V. L. Smith ve A. Williams, "Individual rationality, market rationality, and value estimation", American Economic Review Papers and Proceedings, 52, 1985, s. 397-402.

Sayfa/Page | 143

İGÜSBD

Cilt: 3 Sayı: 2

Ekim /

October 2016 
Sayfa/Page | 144

Örneğin, bir yatırımcı bir yatırım uzmanının Endeks için 72 bine kadar yükselir dediğini duymuş ve endeks 71.500 'den dönmüşse, o yatırımcı için söz konusu yatırım uzmanı hiçbir şeyden anlamıyor pozisyonuna gelir. Aynı şekilde, hisse senetleri fiyatlamasındaki üst direnç ve alt destek bölgeleri de yatırımcıların çıpalama yapma eğilimi göstermesine neden olabilmektedir. Mesela, bir yatırımcının elinde bulunan hisse senedinin değeri 8.50'den dönüp 8.30'a düştügünde, çoğu yatırımcı 8.50 'de satmak içgüdüsüyle hareket edecektir ve bu seviye direnç seviyesi haline gelecektir veya hisse senedinin değeri 8.10 seviyesine gelip oradan yukarı yönlü hareket ediyorsa ve bunu en az iki kere yapmışsa, artık yatırımcı için hisse senedini satın alma noktası 8.10 olur. Söz konusu hisse senedinin değeri $8.05^{\prime}$ e düştüğünde ise artık yatırımcının satmasına imkan yoktur. Çünkü hisse senedinin değeri hakkında ilk elde ettiği izlemini kolay kolay değiştiremez. Hisse senedinin değerinde yaşanan aşağı yöndeki hareketi piyasada kendisinin elinden hisse senedini almak isteyenlerin bilinçli bir şekilde yaptığını, kısa zaman sonra değerin tekrar yukarı hareket edeceğini düşünür. Oysa rasyonel yatırımcı net finansal verilerle reel gerçekler üzerinde dinamik bir yatırım planı izler. Değişen şartlara yeni finansal değerlemelerle ayak uydurmaya çalışır. Kısacası yatırım kararlarına yeni finansal eşikler oluşturur.

\subsection{Yanlış Görüş Birliği}

İnsanlar kendine ait olan görüşlerinin diğer insanlar tarafından da paylaşıldığı veya benimsendiği konusunda iyimser olma eğilimi içerisindedirler. Örneğin, borsanın yükselmesi beklentisindeki bir yatırımcl, borsanın düşeceğini belirten zıt bir görüşe tepki duymakta, uzmanlar tarafindan yapılan uyarılara bu nedenle kulak asmamaktadırlar. Bu durumda yatırımcılar, ne kadar bilgili olursa olsun, zıt görüş sunan birinin yanlış bildiğini varsaymakta ve hatta onu kötü niyetli olmakla suçlayabilmektedir. Hele ki bir yatırımcı bir hisse senedinde belirli bir pozisyon almışsa, o hisse senedi ile ilgili görüşleri tarafsız bir şekilde okuyamaz. Yatırımcılar bu özelliklerinden dolayı karşıt görüşe kapalı olabilmekte, sonucunda ise rasyonel yatırım kararı almakta zorlanabilmektedirler.

\subsection{Duygusal Etkilenme}

İnsanlar, tersini doğrulayan bilgiler olmasına rağmen, duyguların etkisi altında kalarak kayıptan kaçma içgüdüsüyle yaşanan olaylarda pozitif yanların varlığına inanma eğilimi içerisindedirler. Bu kapsamda, bireyler duygusal 
davranarak olayları tüm gerçekliği ile kabul etmeyi reddeder, pozitif yanlarına yoğunlaşmayı tercih ederler. Bu davranış biçimi, aşırı güven ve iyimserlikten sonra en önemli önyargılı algılama davranış biçiminden biridir.

$\mathrm{Bu}$ durum, yatırım kararları alırken, yatırımcıların gerçekten uzaklaşmalarına, doğru analiz yapamamalarına yol açar. Bu tür önyargılı algılama davranışlarından yatırımcılar zaman içerisinde kaçınabilmekle beraber, tamamen kurtulmaları insanın doğası gereği neredeyse imkansızdır. Rasyonel yatırımcılar ise, bu tür önyargılı algılama davranış biçimlerinden uzak durmak için veri ve analizleri sentezleyerek gerçekler üzerinden hareket eder.

\section{DAVRANIŞSAL FİNANS MODELLERİ}

Davranışsal finans alanında yapılmış olan çalışmaların en başında; Barberis, Shleifer ve Vishny (1998)'in, "temsili yatırımcı" modeli, Daniel, Hirshleifer ve Subrahmanyam (1998)'in "aşırı güven ve kendine yükleme" modelleri, Hong ve Stein (1999)'in "karşıllıklı etkileșen ilişkiler" modelleri bulunmaktadır.

\subsection{Temsili Yatırımcı Modeli}

Barberis, Shleifer ve Vishny tarafından geliştirilen "Temsili Yatırımcı" modeli, davranışsal finansı iki yatırımcı davranış eğilimi üzerinden ifade etmektedir. Bu eğilimler "muhafazakârlık eğilimi" ve "temsiliyet etkisi" eğilimidir. "Muhafazakârlık eğilimi" insanların yeni bir görüşe uyum sağlayabilme konusunda zorluk çekmelerini ifade eden bir davranış eğilimidir. Muhafazakârlık eğiliminin nedeni, inançların güncellenmesinin veya yeni bilgi edinmenin insanoğlu için oldukça maliyetli olmasıdır. Finansal piyasalardaki karşılığı da, yatırımcıların daha önce yatırım yaptıkları hisse senetleri hakkında piyasaya, o hissenin değerini olumsuz yönde bir etkilenmeye sürükleyebilecek bir haber ulaştığında dahi daha önceki görüşlerinde bir değişme yapmaksızın o hisseyi tutmaya devam etmesi olarak ortaya çıkabilir. Önyargılarına sıkıca bağlı olan muhafazakâr yatırımcı, daha önce yatırım yapmadığı yatırım araçlarına ve kendinin benimsemediği yeni bilgilere direnç gösterir. Halbuki finansal piyasalar asla statik değildir, rasyonel yatırımcının yeni bilgiye ve fırsatlara daima açı olması dinamik kararlar alması gerekmektedir.

Sayfa/Page | 145 
Sayfa/Page | 146

İkinci yatırımcı davranış eğilimi ise, bir olay, kişi ya da durumu değerlendirirken başka bir olay, kiși ya da durum tarafından temsil edilip edilmediğine bakılarak değerlendirilmesini ve en çok göze çapan unsurlardan etkilenerek karar vermesini ifade eden "temsiliyet etkisi"dir. Bu etki ile yatırımcı piyasada oluşan ve belli bir süre devam eden durumu genelleme olarak kararlarına uygular, bu durum yatırımcının piyasa koşullarına aşırı tepki göstermesine yol açar. Aşırı tepki ise yatırımcların yeni bilgilere daha çok ağırlık verip, eski bilgileri ise yeni bilgilere kıyasla göz ardı etmesi sonucunda, fiyatları pozitif ya da negatif yönde yanlıș değerleyip, daha sonra bu hatayı fark etmiş olsa bile uzun ve/veya kısa vadede yatırımcı konumunu sürdürmesi ile sonuçlanır.

Belirli bir dönemi örnekleme olarak almak ve sonucunda genelleme yapmak her zaman yanlış değildir. Fakat önemli olan peş peșe gerçekleşen olayların birbirleriyle ne kadar ilişkili olduğunu çok iyi analiz etmektir. Örneğin yazı tura atılırken, gelecek sonucun ne olacağı daha önceki yazı tura oyunlarının sonucuna bağlı değildir. Bu durumda sonuç olarak yazı ya da tura gelme olasılığı her yazı tura atıldığında aynıdır. Bu sebeple, yazı tura atarken belli bir süre en çok yazı gelmiş olması, bir sonraki seferde de yazı geleceği, ya da tam tersi bir şekilde çok fazla yazı geldiğinden dolayı bu sefer tura geleceği anlamını taşımaz. Yapılan genelleme insanı yanılgıya itmektedir. Fakat eğer bir deste iskambil kağıdından peş peşe dört vale çekilirse, bir sonra çekilen kağıt için vale olmaz tahmininde bulunmak akıllıca olacaktır, çünkü bu durumda olaylar birbirleri ile ilişkili haldedir. Finansal piyasalarda karşılaşılan durumlar elbette bu örneklerdeki kadar basit değildir, bu yüzden rasyonel yatırımcının sebep-sonuç ilişkilerini analiz ederken birçok farklı değişkeni göz önünde bulundurması, analizlerini bilgiye dayandırması, genellemelerden kaçınması gerekmektedir.

\subsection{Aşırı Güven ve Kendine Yükleme Modeli}

"Aşırı güven" eğilimi daha önce de ele alındığı üzere kişilerin yetenekleri ve karar verme becerileri konusunda kendilerine aşırı bir güven gösterme ve genel olarak diğer insanlardan üstün görme eğiliminde olma hallerini ifade eden bir yatırımcı davranışıdır. "Kendine yükleme" eğilimi ise insanların genel olarak başarıyı kendinden bilmek, başarısızlığı ise dış faktörlere bağlamak eğilimini ifade etmektedir. ${ }^{13} \mathrm{Bu}$ iki davranış şekli genellikle birbirleriyle

${ }^{13}$ Ali Yörükoğlu, "Davranışsal Finans", Yayınlanmamış Yüksek Lisans Tezi, Marmara Üniversitesi Bankacılık ve Sigortacılık Enstitüsü, İstanbul, 2007, s. 63-64. 
ilişkidir. Kendine aşırı güven sahibi insanlar, yaptıkları hataların nedenini kendinde göremeyerek dış faktörleri suçlama eğiliminde olurken, her başarının nedenini de kendinde görmektedir.

Yatırımcılar yatırım kararları alırken bu tür önyargılı algılama davranışları nedeniyle irrasyonel davranma eğiliminde olabilmektedirler. Zaman ile kazanılan tecrübe bu tür önyargılı davranışları elbette azaltmaktadır. Fakat insanoğlunun karmaşık iç dünyası ve her daim rasyonel olmayan davranışlarının yatırım kararlarının sağlıklı olması açısından kontrol altına alınması ancak rasyonel güçlerin yaygınlaşması ile gerçekleşir.

\subsection{Karşılıklı Etkileşen İlişkiler Modeli}

$\mathrm{Bu}$ model, yatırımcılar arasındaki karşılıklı etkileşen ilişkilere dayanılarak ortaya konmuştur. Bu karşılıklı etkileşen ilişkileri betimlemek için ise iki tür yatırımcı profili geliștirilmiștir. Bunlar: "bilgi avcıları" ve "momentum yatırımcıları"dır. ${ }^{14}$

Bilgi avcıları, tahminlerini tamamen geleceğe dair gözlemlerinden hareketle gerçekleştirirken, mevcut ve geçmişe dair bilgileri tahminlerinde kullanmakta yetersiz kalmaktadır. Bu tip yatırımcıları, herhangi bir hisse senedini değerlendirirken temel analizi kullanan ancak teknik analiz kullanmakta yetersiz kalan bir yatırımcıya benzetmek mümkündür.

Momentum yatırımcıları ise bilgi avcılarının tam tersi bir yapı gösteren yatırımcılardır. $\mathrm{Bu}$ tip yatırımcılar, yatırım tahminlerinde geleceğe dair bir tahminlemeden hareket etmeyerek, tamamen geçmiş fiyat hareketlerinden bir takım tahminlerde bulunma yöntemini kendilerine seçmiş yatırımcılardır. $\mathrm{Bu}$ tip yatırımcları da tanımlamada, tahminlerinde temel analizden uzak duran, tamamen teknik analizle hareket eden yatırımcılar olarak tanımlamak mümkündür.

Piyasada oluşan her türlü bilgi ve verinin yatırım kararları açısından bir önemi bulunmaktadır. Sermaye piyasalarında sistematik ve sistematik olmayan olmak üzere iki ana bilgi kaynağı bulunmaktadır. Sistematik bilgi, menkul kıymetlerin fiyatlarına etki edebilecek, piyasa koşulları ve

${ }^{14}$ Harrison Hong ve Jeremy Stein, "A Unified Theory of Underreaction, Momentum Trading and Overreaction in Asset Markets", Journal of Finance, Cilt: 54, Sayı: 6, 1999, s. 2144 .

Sayfa/Page | 147 
Sayfa/Page | 148

makroekonomik göstergeler gibi genel bilgilerdir. Sistematik olmayan bilgiler ise; temettü ödeme kararları, firma birleşme ve devirleri, fiyat/kazanç oranı, yeni ihraç kararları ve mali tablolar gibi ihraççı şirkete özel bilgilerdir. Yatırımcıların sağlıklı yatırım kararları alması doğrultusunda her iki bilgi kaynağını da teknik ve temel analizlerinde kullanması gerekmektedir. Yatırımcının bilgi düzeyi bu yüzden oldukça önemlidir ve yatırım amaçlarına ve risk profiline uygun olan yatırım kararları almasına yardımcı olur. Yatırım yapma kararlarında yararlanılan en temel şey bilgidir. Yatırımcıların piyasalarda yer alan bilgi türlerini bilinmesi, o bilgilerin elde edilebileceği kaynakların belirlenmesi ve hangi tür analizde kullanacağını saptaması açısından da büyük bir öneme sahiptir. Bilgi yatırım kararı alırken yatırımcılar açısından en temel yapı taşıdır, analiz türleri ve hangi tip analizleri hangi durumda kullanmaları gerektiği yatırımın temelini oluşturur. Bununla birlikte yatırımcıların yatırım kararlarını alırken davranışsal finansın ortaya koyduğu irrasyonel davranış şekillerinin de bilincinde olmaları yatırım kararlarının başarısının devamlılığı için elzemdir. Birbirleriyle oldukça girift bir biçimde etkileşim halinde olan bu olgular tecrübenin yanında, finansal eğitim ile yatırımcılara aktarılabilir.

\section{Sonuç}

İnsanoğlu, çok karmaşık yapıya sahip bir varlıktır. Bu anlamda, özellikle piyasa anomalileri ve son dönemlerde yaşanan krizler sonrası, klasik iktisat teorilerinde varsayılanın aksine, insanın bazı zamanlarda doğru olmadığını bildiği adımları atabildiğini göstermiştir. İnsanı rasyonel bir varlık olarak nitelendiren klasik ekonomi ve finans teorilerinde yer almayan bu insani özellikler, ekonomi ve finans alanına yeni bir bakış açısı kazandıran Davranışsal Finans ile gündeme gelmiştir. Davranışsal Finans, gerçek hayata daha uygun ve insanı merkezde tutan teoriler ile finans alanının içerisine psikoloji, sosyoloji ve nöroloji gibi diğer sosyal bilimleri de sokmaktadır. Bu özelliğinden dolayı da, gelecek yıllarda, insanı bütün çıplaklığı ile merkezine alan Davranışsal Finans teorisinin ekonomi ve finans alanında daha fazla yer elde edeceği de öngörülmektedir.

Yatırımcıların doğru karar alabilmesi birçok değişkeni aynı anda yorumlayabilmesi, her türlü bilgiyi, geçmiş gözlemleri dikkate almasının yanında gelecek tahminleri de göz önünde bulundurması ile mümkündür. $\mathrm{Bu}$ nedenle, oldukça detaylı analizleri gerektiren yatırım kararları, ancak finansal okuryazarlık seviyesinin yüksek olması ile sağlıklı bir şekilde gerçekleşebilir. Yatırımcıların piyasa deneyim ve tecrübeleri ile finansal bilgi seviyesi, yatırım 
kararlarında diğer yatırımcılardan daha fazla getiri elde etmesini sağlar. Bundan dolayı yatırımcıların öncelikle piyasada yaratılan algılardan ve kendi düşünsel zaaflarından arındırılarak bilinçlendirilmesi ve eğitilmesi gerekmektedir. Yatırımcı kendisinin ve yatırım araçlarının iyi ve kötü yönleri ile tanıması, yatırımlarının olası risk ve getirileri hakkında tam ve doğru bir bilgi sahibi olması, yatırım kararlarını rasyonel bilgi ve belgelere dayandırması ve bu çerçevede şekillendirmesi en sağlıklı yatırım şeklidir.

\section{KAYNAKÇA}

BODIE, Zvi, Alex KANE ve Alan J. MARCUS, Investments, 8th ed., Mc Graw Hill Yayınevi, Singapur, 2009.

CASE, K. E. ve R. SHILLER, "The behavior of home buyers in boom and post-boom markets", New England Economic Review, 80, 1990.

ERDEM, Orhan, "Değișen Teoriler ve Davranıșsal Finans", 26 Ağustos 2015, http://www.bilgi.edu.tr/site media/uploads/files/2015/08/26 Lekonomide-paradigma-150824.pdf? , (Erişim Tarihi 16 Ocak 2015).

HONG, Harrison ve C. Jeremy STEIN, "A Unified Theory of Underreaction, Momentum Trading and Overreaction in Asset Markets", Journal of Finance, Cilt: 54, Sayı: 6, 1999.

KAHNEMAN, Daniel ve Amos TVERSKY, "Subjective Probability: A Judgment of Representativeness", Cognitive Psychology, Vol:3, 1972.

KAHNEMAN, Daniel ve Amos TVERSKY, "Judgment Under Uncertainty: Heuristics and Biases", Science, Vol:185, 1974, s. 4157.

KNEZ, P., V. L. SMITH ve A. WILLIAMS, "Individual rationality, market rationality, and value estimation", American Economic Review Papers and Proceedings, 52, 1985, s. 397-402.

LANGER, E. J. ve J. ROTH, "Heads I win, tails it's chance: The illusion of control as a function of the sequence of outcomes in a purely chance task", Journal of Personality and Social Psychology, 32, 1975, s. 951-955.

MILLER, M. ve F. MODIGLIANI, "Dividend policy, growth, and the valuation of shares”, Journal of Business, 34 (4), 1961, s. 411-433.

NOFSINGER, John R., The Psychology of Investing, 4th ed., NJ: Prentice-Hall, 2010.

SCHRAGE, Michael, "Daniel Kahneman: The Thought Leader Inteview", Strategy + Business, 2003.

TREPEL, C., C. R. Fox ve R. A. POLDRACK, "Prospect theory on the brain? Toward a Cognitive Neuroscience of Decision Under Risk", Cognitive Brain Research, 2005.

Sayfa/Page | 149 
YÖRÜKOĞLU, Ali, “Davranışsal Finans”, Marmara Üniversitesi Bankacılık ve Sigortacılık Enstitüsü, İstanbul, 2007, (Yayınlanmamış Yüksek Lisans Tezi).

\section{Summary}

The notion of "rationality" is one of the basic assumptions of neoclassical economics. Economic rationality assumes that individuals base decisions within the most optimal state. However, especially after the recent financial crisis, it is agreed that this approach took a more constricted interpretation of human behaviors and cannot explain market anomalies accurately. Thus, modern economic theories started to focus on exploring human actions and decisionmaking processes that go beyond the basic assumptions of the neoclassical model.

Behavioral Finance was born with this intention in mind, as a discipline that includes psychology, sociology and neurology to describe the complex course of decision-making and market anomalies which cannot be explained by traditional finance. Studies in Behavioral Finance propose that a more advanced model of human drives is essential to describe behaviors such as those that initiate to stock market fluctuations, anomalies and why individuals every so often seem to work against their own self-interest. Rather than constructing norms about human behavior, behavioral finance relies severely on scientific experiments to define how individuals act in different circumstances.

In this work, some elementary assumptions and works of Behavioral Finance is examined in terms of investor decisions, limitations and influences. 